\title{
Correlates of Science Concept Acquisition: Foundations for Better Doctors, Engineers, and Scientists
}

\author{
Sarah Shahed, ${ }^{1}$ Madiha Rauf Hashmi, ${ }^{2}$ Ali Madeeh Hashmi ${ }^{3}$
}

\begin{abstract}
Background: School prepare students for successful professional careers. Evidence indicates that the quality of science education in schools is deteriorating andstudents may not bedeveloping the conceptual understanding of science required for success in later life. This may be one of the causesofdearth of research scientists in the country.

Objective: The present study was conducted to study science concept acquisition and related variables in secondary school students in Punjab Province.

Method: A survey was conducted involving a purposive sample of 720 male and female students of class 9 in both science and humanities groups in public sector schools in six districts of Punjab covering the central,
\end{abstract}

Date of Submission 14-11-2015

Date of Revision Received 19-1-2016

Date of Acceptance for Publication 29-1-2016

Conflict of Interest: None

Funding Source: None

Shahed S. ${ }^{1}$

Department of Gender and Development Studies

Lahore College for Women University

Hashmi M.R. ${ }^{2}$

Department of Gender and Development Studies

Lahore College for Women University

Hashmi A.M. ${ }^{3}$

Department of Psychiatry and Behavioral Sciences

King Edward Medical University/ Mayo Hospital, Lahore southern and northern region of the province. The Science Concept Acquisition Test and a self - constructed questionnaire were used for data collection.

Results: The findings of this study revealed that variables like class size, teaching methodology, academic group and city were important in the performance of students in science. The study also yielded gender differences in test scores.

Conclusion: It is suggested that the school authorites and all stakeholdersneed to take steps to improve the quality and learning outcome of science education in Pakistan.

Keywords: Concept Acquisition , Rote Memorization, Gender, Teaching methodology, academic group.

\section{Introduction}

Attempts have been made in recent years to improve the quality of science education in Pakistan.It is important that the learners are able to apply the learnt concepts of science in daily and professional life which empowers learners to form conclusions and generalizations based upon the information accumulated with the passage of time. ${ }^{1}$ However many students unfortunately have a very poor foundation in science literacy and therefore may remain unable to apply the formally studied concepts in their practical life. This represented a significant rate of science pupils dropping science subjects in the later year because conceptual under standing had not been obtained. ${ }^{2}$

In Pakistani school settings, particularly state funded schools, the emphasis of learning is on retention and rote memory. Thusstudentsdo enough to get through the next test but do not necessarily grasp the information. ${ }^{3,4}$ According to the census, the proportion of enrollment in science to enrollment in humanities, 
aggregate at 9th grade is 2:1 in Pakistan ${ }^{5}$ which reflects that our educational framework is still unable to attract of people towards science subjects. In an attempt to understand the theoretical understanding of conceptual knowledge in pupils, educator and social research specialists have found out variables which help in successfully imparting the practical and conceptual knowledge among students. The role of many factors has been discussed and considered critical to promote scientific conceptual learning in students by many researchers which are; sex, the school environment, student factors, teacher factors, nature of subject, Government policies, and so on. ${ }^{6-9}$ Besides this, class size and teaching methodology were also explored $^{10,11}$ as important elements of student achievement in school, particularly in sciences.

Numerous researchershave found huge contrasts between male and female students in science accomplishment and uncovered a noteworthy gender impact favoring boys in science accomplishment. ${ }^{12-15}$ Other researchersreported conceivable clarifications for why females perform lower than males in science by highlighting differences, in educational assistance, parental support, inspiration, registration aspect, and practical experience. ${ }^{16-18}$

Class size is of vital importance in students also matters. As the number of students in school increases, class size also increases which creates problems for teachers in giving attention to each student. Studies indicate that class sizecan impact students' emotions, academicaccomplishment, school quality and educational standard ${ }^{19}$ and lower scholastic accomplishment. ${ }^{20}$ Another study found there was no huge distinction in the post - test accomplishment scores between large classes and small classes. ${ }^{21}$ UNESCO reported 34 as a normal class size in states associated with World Education Indicator program (WEI) and 24 in member countries of Orgnization for Economic Development and Cooperation. ${ }^{22}$ Concerning teaching methodology, academic literature proposes that abstract understanding of science canbe obtained if right instructional strategy is used. Researches have discovered that students grasp the concept well when they have a chance to use scienctific facilities and instruments practically. ${ }^{23-26}$

A wide range of variablescan thus influence the academic achievement ofstudents and it is important to distinguish those which might impact science concept acquisition among students. This study attempted to examine young school students'grasp over general science concepts and whether it changes in the pre- sence of personal and school related factorssuch as gender, academic group, instructional technique, class size, city and marks obtained in class $8^{\text {th }}$.

\section{Objectives of the Study}

The main objectives of the present study were to:

- Assess the students' concepts of science being imparted in Government schools.

- Investigate the contributing school related variables oflearning conceptual science in schools.

- Explore gender differences in the acquisition of science concepts.

- Provide a set of recommendations for improvement in science teaching methodologies, science curriculum and science teacher education programs in Pakistan in the light of the findings of the present study.

\section{Method}

This descriptive study was conducted by using the survey method. This research was designed by using quantitative research method to investigate gender difference and possible related influential variables regarding science concepts acquisition in secondary public schools' students. The total sample size of this study was 720 enrolled student both girls and boys of class $9^{\text {th }}$ (360 female and 360 male students) from six districts of Punjab (Lahore, Gujrat, Rawalpindi, Jhelum, Multan and Bahawalpur) covering the northern, southern and central region of the province. Students were selected by using purposive sampling from 14 public secondryschools ( 7 girls secondry schools and 7 boys secondary schools) in six districts. From selected governmentschoolsa class of 60 male students and 60 female students each (30 from science and 30 from Arts/Humanities group) were selected. Only those secondry schools were selected where boys and girls enrolled in arts and science groups were easily accessible. The Science Concepts Acquisition Test (SC$\mathrm{AT})^{27}$ was used to measure the science achievement among students. It is a 40 - item multiple choice objective testcovering the items related to basic science concepts. The scoring was done with the help of key, so that number of correct answers yield students ' score. A separate proforma was used for getting information regarding school related variables and demographics. Oneway Analysis of Variances (ANOVA), Post 
Hoc Tukey's HSD, t-test and correlation were used to test the hypotheses of the study. All tests were measured by using SPSS.

\section{Results}

360 female and 360 male students with mean age 15.13 were participated in this study. Equal number of female andmale students enrolled in science and arts groups were selected. Mean score of the SCAT recorded in this study was 22.39 . Additionally $55.8 \%$ students experienced lecture method as a teaching strategy used in their science classes whereas $44.2 \%$ students experienced lecture with practical methods in their schools.

Table 1: Independent sample t-test measuring the difference in SCAT scores of the students $(n=60)$.

\begin{tabular}{|c|c|c|c|c|c|}
\hline \multicolumn{2}{|c|}{ Factor } & Mean & $\mathrm{SD}$ & $t$ & $\mathrm{p}$ \\
\hline \multirow[b]{2}{*}{ Gender } & Female & 21.93 & 5.29 & & \\
\hline & Male & 22.87 & 5.88 & -2.259 & $.024 *$ \\
\hline \multirow[b]{2}{*}{ Academic Group } & Arts/Humanities & 20.97 & 6.03 & & \\
\hline & Science & 23.83 & 4.74 & 7.065 & $.000 * *$ \\
\hline \multirow[b]{2}{*}{ Teaching Methodolgy } & Lecture & 21.85 & 5.66 & & \\
\hline & Lecture with Practical & 23.08 & 5.47 & -2.93 & $.003 * *$ \\
\hline
\end{tabular}

$* \mathrm{p}<.05 \quad * * \mathrm{p}<.01$

Table 2: Independent sample t-test measuring the difference in test score of the students of different cities.

\begin{tabular}{|c|c|c|c|c|c|}
\hline \multicolumn{2}{|c|}{ Factor } & Mean & $\mathrm{SD}$ & $t$ & $\mathrm{p}$ \\
\hline \multirow{3}{*}{ Lahore } & Female & 20.70 & 4.89 & \multirow{3}{*}{.84} & \multirow{3}{*}{ ns } \\
\hline & Male & 19.90 & 5.47 & & \\
\hline & Total & 20.3 & & & \\
\hline \multirow{3}{*}{ Gujrat } & Female & 20.51 & 3.46 & \multirow{3}{*}{-6.29} & \multirow{3}{*}{$.000^{*}$} \\
\hline & Male & 24.53 & 3.51 & & \\
\hline & Total & 22.52 & & & \\
\hline \multirow{3}{*}{ Rawalpindi } & Female & 20.88 & 5.32 & \multirow{3}{*}{-4.02} & \multirow{3}{*}{$.000 *$} \\
\hline & Male & 24.65 & 4.92 & & \\
\hline & Total & 22.77 & & & \\
\hline \multirow{3}{*}{ Pind Dadan Khan } & Female & 23.83 & 3.83 & \multirow{3}{*}{-.53} & \multirow{3}{*}{ ns } \\
\hline & Male & 24.23 & 4.28 & & \\
\hline & Total & 24.03 & & & \\
\hline \multirow{3}{*}{ Multan } & Female & 22.91 & 7.41 & \multirow{3}{*}{3.86} & \multirow{3}{*}{$.000 *$} \\
\hline & Male & 17.96 & 6.58 & & \\
\hline & Total & 20.44 & & & \\
\hline \multirow{3}{*}{ Bahawalpur } & Female & 22.71 & 5.13 & \multirow{3}{*}{-3.25} & \multirow{3}{*}{$.001 *$} \\
\hline & Male & 25.93 & 5.58 & & \\
\hline & Total & 24.32 & & & \\
\hline
\end{tabular}

$* \mathrm{p}<.05 \quad * * \mathrm{p}<.01$
The result showed that there was a significant difference in Science Concept Acquisition Test scores of male and female students of class 9. The mean score indicated that male students scored better in SCAT test and the difference between the two groups was significant. Additionally, the mean of science group students was found to be significantly greater than the humanities group. The analysis about using different teaching methodologies shows that the student taught by lecture plus practical method scored significantly higher than the student taught by lecture only method.

The results indicated that students of Bahawalpur and Pind Dadan khan secured the highest average score on SCAT. There was a significant difference in the Science Concept Acquisition scores of male and female students belonging to different districts of Punjab except Lahore and Pind Dadan Khan. The mean score indicated that male students of Gujrat, Rawalpindi and Baha walpur 
scored better in SCAT test, whereas female students of Multan city scored higher in the SCAT than boys.

Table 3: Analysis of Variance of Test Scores of students across six districts.

\begin{tabular}{|c|c|c|c|c|c|}
\hline Variable and Score & SS & df & & $\mathrm{F}$ & $\mathrm{P}$ \\
\hline Between Groups & \multicolumn{4}{|c|}{1772.225354 .4412 .13} & .000 \\
\hline Within Groups & \multicolumn{4}{|c|}{$\begin{array}{lll}20854.37 & 714 & 31.09\end{array}$} & 29.20 \\
\hline Total & \multicolumn{4}{|c|}{$22626.59 \quad 719$} & \\
\hline
\end{tabular}

$*$ F value significant at $\mathrm{p}<.05$

The students' scores across six districts were further analyzed through ANOVA. The result reflected significant differences in students' SCAT scores belonging to six districts of Punjab, F $(5,714)=12.13$, $\mathrm{p}<.05$. This was further analyzed in the post hoc Tukey's HSD comparison. The SCAT scores of students indicate that the students belonging to Rawalpindi $(\mathrm{M}=22.76, \mathrm{SD}=5.44)$, Gujrat $(\mathrm{M}=22.52$, $\mathrm{SD}=4.02)$, Pind Dadan Khan $(\mathrm{M}=24.03, \mathrm{SD}=4.05)$ and Bahawalpur $(\mathrm{M}=24.32, \mathrm{SD}=5.58)$ scored better than the students of Lahore $(M=20.30, S D=5.18)$. Additionally, students of Rawalpindi $(\mathrm{M}=22.26$, $\mathrm{SD}=5.44)$, Gujrat $(\mathrm{M}=22.52, \mathrm{SD}=4.02)$, Pind Dadan Khan $(\mathrm{M}=24.03, \mathrm{SD}=4.05)$ and Bahawalpur $(\mathrm{M}=24.32, \mathrm{SD}=5.58)$ scored better than the students of Multan $(\mathrm{M}=20.44, \mathrm{SD}=7.41)$.

Table 4: Analysis of Variance of Test Scores of students across class sizes.

\begin{tabular}{|l|lllllr|}
\hline Variable and Score & SS & df & MS & F & P \\
\hline Between Groups & 337.045 & 2 & 168.52 & 5.421 & .005 \\
Within Groups & 22289.45 & 717 & & 31.09 & \\
Total & 22626.59 & 719 & & & \\
\hline
\end{tabular}

$*$ F value significant at $\mathrm{p}<.05$

The SCAT scores of students differed significantly across their class sizes in public schools $F(2,717)=$ $5.421, \mathrm{p}<.05$. This was further analyzed in the post hoc Tukey's HSD comparison. The results indicated that the students' group whose class size was less than $30(\mathrm{M}=23.88, \mathrm{SD}=.6 .31)$ scored significantly higher on SCAT than the group of students with class size 30
$(\mathrm{M}=21.24, \mathrm{SD}=5.54)$ and the group of students with more than 30 class size $(\mathrm{M}=22.35, \mathrm{SD}=5.44)$. Other comparisons between groups did not yield any statistical differences at $\mathrm{p}<.05$.

The pearson correlation between total score and science marks gained in annual examination was calculated. The analysis yielded a relationship between the students 'science subjects marks gained in annual examination of class 8th with the SCAT test scores of students in this study.

\section{Discussion}

The findings revealed the gender differences in SCAT scores. Moreover, the overall performance of male students was found to be better than that of females which is consistent with numerous other studies. ${ }^{12,14,15}$ The possible explanation of this difference as also mentioned by other researchers can be the differences in teachers' and parental support, motivation, enrollment patterns, and practical experience. ${ }^{16-18,28-30}$ Our study also highlighted gender differences in test scores of students belonging to six districts of Punjab.The result indicated that male students of Gujrat, Rawalpindi and Bahawalpur scored better in SCAT test, whereas girl students of Multan city scored higher in the SCAT than boys. Moreover, our finding revealed that students of Gujrat, Rawalpindi, PindDadan Khan and Bahawalpur performed better in SCAT than students of Lahore and Multan. An explanationof these results might be the differences in facilities available in schools and different teachings methodologies practiced in schools by teachers. Furthermore, individual difference in attitude towards science can be a crucial which should be further investigated. Students of humanities study Science for their first ten years in school; however, their performance in science is not as good as that of a science student. There is a dearth of research on this subject. It may be due to factors such as students' motivation or attitude. Other possible reasons can be thatteachers and parents pay more attention to a child studying science subjects. However, this needs to be further explored.

The finding of this study revealed that students taught with practical and lecture method scored higher in SCAT scores than those taught only by lecture method. Many previous studies support this finding. ${ }^{23-26,31}$ The use of effective teaching methodology has remainned apoint of critical debate in literature for many years. Many researchers have emphasized practical 
methods for effectively gaining science concepts. ${ }^{32,33}$ In our study, we verified thatstudents in public schools taught with practical demonstrations along with conventional methods gain greater understanding of concepts.

Our findings suggest that there are significant differences in the test scores of students across different class sizes. The results further indicated that students in a smaller sized class, less than thirty, scored higher than students in a class size of thirty and more than thirty students per class. This is consistent with prior literature findings. ${ }^{34,35}$ Most public schools have large sized classes. However, students who had the opportunity to study in smaller classeswere found to perform better since they get time to discuss their academic issues with their teachers and teachers can provide more time for discussion and practical work..$^{20}$

Controlling class size can thus have a significant effect on learning andachievement in science.

Another significantfinding of the present study was the positive correlation between the test scores of students with marks obtained in the science subject in their final examination of class 8th. SCAT scores can be good indicators ofstudents'performance in exams and can be utilized for future research.

\section{Conclusion}

It is imperative to have an understanding of the factors that promote and hamper students' conceptual understanding of science taught in schools. This study concentrated on some of the variables related to schools that influence the students' performance in SCAT scores and found many of them to be significantly related with science concept acquisition.

\section{Future Implication}

Teachers need to educate their students so that they improve their academic performance as well as to be able to apply the acquired concepts in later life. Our study reported that smaller class size, less than 30 , can improve the understanding of students regarding scientific concepts. Our schools need to make this a priority. The authorities can also help by formulating policies regarding maximum slasssize. Teachers in public schools should incorporate the use of practical demonstrations in order to develop better understanding of different scientific concepts in students. The government can play its role by arranging trainings and ref- resher courses for teachers to equip with new teaching techniques and ensuring the provision of all necessary instruments for practical work in public schools. Science curricula need to be revised and updated to make them practical and interesting for students.

\section{References}

1. Mohanty R. Science Education Programme in Secondary Schools. Deep and Deep Publications; 2004.

2. Hussein F, Reid N. Working memory and difficulties in school chemistry. Res Sci Tech Edu. 2009 Jul 1; 27 (2): 161-85.

3. Memon GR. Education in Pakistan: The key issues, problems and the new challenges. J Manag Soc Sci. 2007; 3 (1): 47-55.

4. Sadiq A. Evaluation of Scientific Enterprise in Pakistan. Towards Understanding the State of Science in Pakistan. Karachi, Muizz Process, 2003.

5. Pakistan Education Census, 2005.

6. Iqbal HM, Nageen T, Pell AW. Attitudes to school science held by primary children in Pakistan. Eva Res Edu. 2008 Nov 1; 21 (4): 269-302.

7. Prophet RB. Rhetoric and reality in science curriculum development in Botswana. Int J Sci Educ. 1990 Jan 1; 12 (1): 13-23.

8. Liu X. Synthesizing research on student conceptions in science. Int J Sci Educ. 2001 Jan 1; 23 (1): 55-81.

9. Yip DY. Promoting the development of a conceptual change model of science instruction in prospective secondary biology teachers. . Int J Sci Educ. 2001 Jul 1; 23 (7): 755-70.

10. Allen J, Lynd C. Debunking the Class Size Myth: How to Really Improve Teacher Quality. The Center for Education Reform, 2000.

11. Odubunmi O, Balogun TA. The effect of laboratory and lecture teaching methods on cognitive achievement in integrated science. J ResSci Teac. 1991 Mar 1; 28 (3): 213-24.

12. DeBaz TP. Meta - Analysis of the Relationship between Students' Characteristics and Achievement and Attitudes toward Science, 1994.

13. Lee VE, Bryk AS, Smith JB. The organization of effective secondary schools. Rev Res Edu. 1993 Jan 1: 171267.

14. Beller M, Gafni N. 1991 International Assessment of Educational Progress in Mathematics and Sciences: The gender differences perspective. J Edu Psy. 1996 Jun; 88 (2): 365 .

15. Amelink C. Literature overview: Gender differences in science achievement. SWE - AWE CASEE Overviews, 2009.

16. Desouza JM, Czerniak CM. Social behaviors and gender differences among preschoolers: implications for 
science activities. J Res Child Edu. 2002 Jun 1; 16 (2): 175-88.

17. Enman M, Lupart J. Talented female students' resistance to science: An exploratory study of post-secondary achievement motivation, persistence, and epistemological characteristics. High Abil Stud. 2000 Dec 1; 11 (2): 161-78.

18. Greene BA, DeBacker TK. Gender and orientations toward the future: Links to motivation. Edu Psyy Review, 2004 Jun 1; 16 (2): 91-120.

19. Dror Y. School Size as a Function of Uniqueness, Autonomy, Integration and Comprehensiveness: An historical model with current implications. J Edu Admin history, 1995 Jan 1; 27 (1): 35-50.

20. Adeyela J. Problems of Teaching Science in Large Classes at the Junior Secondary School Level. Implications for Learning Outcome. Unpublished M. Ed Thesis. University of Ibadan, Ibadan. 2000.

21. Afolabi F. School factors and learner variables as correlates of senior secondary physics in Ibadan. Unpublished Ph. D thesis, University of Ibadan, Ibadan, 2002.

22. Harris R, Miske S, Attig G. Embracing Diversity: Toolkit for Creating Inclusive Learning - Friendly Environments. UNESCO Bangkok, 2004.

23. Carrier K. Key issues for teaching learners in the classrooms. Middle Sch J. 2005; 37 (4): 17-24.

24. Hadgraft RG. Problem - based learning: A vital step towards a new work environment. Int J Engi Edu. 1998 Jan 1; 14 (1): 14-23.

25. Blair K, Schwartz D, Biswas G, Leelawong K. Pedagogical agents for learning by teaching: Teachable agents. Edu Tech - Saddle Brook Then Engle Cliffs Nj-. 2007; 47 (1): 56.

26. National Research Council, editor. National science education standards. NAP; 1996.

27. Shahed S. Development of a Test for Assessing Acqui- sition of Science Concepts Among Secondary School Students. J Special Edu .Department of Special Education, University of the Punjab, 1998; 1 (1): 41-48.

28. Mattern N, Schau C. Gender differences in science attitude - achievement relationships over time among white middle - school students. J Res Sci Teach. 2002 Apr 1; 39 (4): 324-40.

29. Shin N, McGee S. The influence of inquiry - based multimedia learning environment on scientific problemsolving skills among ninth - grade students across gender differences. Annual Proceedings - Dallas: Volume \#. 2002: 395.

30. Tenenbaum HR, Snow CE, Roach KA, Kurland B. Talking and reading science: Longitudinal data on sex differences in mother - child conversations in low - income families. J App Develop Psy. 2005 Feb 28; 26 (1): 1-9.

31. Hofstein A, Lunetta VN. The laboratory in science education: Foundations for the twenty - first century. Sci Edu. 2004 Jan 1; 88 (1): 28-54.

32. Cardak O, Onder K, Dikmenli M. Effect of the usage of laboratory method in primary school education for the achievement of the students' learning. In Asia - Pacific Forum on Science Learning and Teaching. 2007 Dec 3 (Vol. 8, No. 2, p. n2). Hong Kong Institute of Education. 10 Lo Ping Road, Tai Po, New Territories, Hong Kong.

33. Ottander C, Grelsson G. Laboratory work: the teachers' perspective. J Bio Edu. 2006 Jun 1; 40 (3): 113-8.

34. Owoeye JS, Yara PO. Class size and academic achievement of secondary school in Ekiti state, Nigeria. ASS . 2011; 7 (6): p184.

35. Fan FA. Class Size: Effects on students'academic achievements and some remedial measures. Res Edu . 2012 May 1 (87): 95. 